\title{
The Estimation of Vitamin $\mathbf{E}$
}

\section{SEPARATION OF TOCOPHEROL MIXTURES OCCURRING IN NATURAL PRODUCTS BY PAPER CHROMATOGRAPHY}

\author{
BY F. BROWN \\ The Hannah Dairy Research Institute, Kirkhill, Ayr
}

(Received 30 August 1951)

The determination of the tocopherol content of biological materials by the ferric chloride-2:2' dipyridyl method (Emmerie \& Engel, 1938) gives results which are of limited value for two reasons. First, the biological activities of the $\alpha-, \beta-, \gamma-$ and $\delta$-tocopherols are in the approximate ratio $100: 30: 20: 1$, depending on the biological test used, whereas all four tocopherols give the same value by the chemical method. Secondly, non-tocopherol substances which also give a red colour with the Emmerie-Engel reagents are often difficult to separate from the tocopherols and it is not always possible to be certain that the interfering impurities have been removed from the solutions which are finally tested (Baxter, Lehman, Hove, Quaife, Weisler \& Stern, 1947).

Differential analysis of the tocopherols can be partly achieved by coupling the $\gamma$ - and $\delta$-compounds with diazotized o-dianisidine (Weisler, Robeson \& Baxter, 1947); the $\alpha$ - and $\beta$-tocopherols do not couple with this reagent. Since $\beta$-tocopherol has been found in wheat products only, values for the total and $\gamma$-plus $\delta$-tocopherol contents of most materials can be obtained by examining for $(a)$ total tocopherols by the Emmerie-Engel method, and (b) $\gamma$-plus $\delta$-tocopherols by coupling with diazotized $o$-dianisidine. The value for $\alpha$-tocopherol can be obtained by subtracting $(b)$ from $(a)$.

The desirability of a method which would allow a clear-cut separation of the tocopherols led Emmerie (1949) to attempt the resolution of the tocopherols by chromatographing on Floridin $X S$ Earth or alumina. Although the $\alpha$ - and $\gamma$-tocopherols could be separated under strictly controlled conditions, mixtures of the $\alpha$ - and $\beta$-tocopherols could not be resolved into the separate components.

Since paper chromatography has found application in numerous problems involving the separation of closely related compounds, attempts have been made in the present work to extend the method to the analysis of tocopherol mixtures made up in the laboratory. Tocopherol mixtures occurring in natural products have also been examined in order to test the utility of the method in distinguishing non-tocopherol reducing substances from authentic tocopherols.

\section{EXPERIMENTAL}

\section{Chromatography}

Both ascending (Williams \& Kirby, 1948) and descending (Consden, Gordon \& Martin, 1944) methods were used. Whatman no. 1 filter paper was coated with Vaseline (Winteringham, Harrison \& Bridges, 1950) by dipping it in a $2.5 \%(w / v)$ solution of Vaseline in ether and then allowing the solvent to evaporate from it in the air. Storage of the coated papers for as long as 2 months before use did not alter their properties. The tocopherols were applied to the papers by means of a calibrated pipette delivering $6 \cdot 3 \mu \mathrm{l}$. Alcoholic solutions of the tocopherols were used to avoid dissolving the Vaseline at the points of application. Various concentrations of methanol, ethanol and acetone in water were each tested for use as the mobile phase and $75 \%$ ethanol $(v / v)$ was finally selected as giving the best separations.

\section{Detection of the tocopherols}

The developed chromatograms were dried for $15 \mathrm{~min}$. at room temperature and then sprayed with $2: 2^{\prime}$-dipyridyl $(0.25 \%, \dot{w} / v)$ in ethanol followed by ferric shloride $(0.1 \%$, $w / v)$ in ethanol. Bright-red spots were formed on a white background. The background gradually assumes a pink colour so the positions of the spots must be marked fairly soon after spraying. In order to obtain a permanent record, methanolic silver nitrate $\left(1.7 \mathrm{~g} . \mathrm{AgNO}_{3}\right.$ in $50 \mathrm{ml}$. water, $33 \mathrm{ml}$. methanol and $17 \mathrm{ml}$. aqueous $\mathrm{NH}_{3}$ sp.gr. 0.880 ) can be used. The dark brown spots appear about 1 min. after spraying, the one corresponding to the $\alpha$-form appearing first and that corresponding to the $\delta$-form last. Spraying with $2 \%(\mathrm{w} / \mathrm{v}) \mathrm{Na}_{2} \mathrm{CO}_{3}$ followed by diazotized $o$-dianisidine solution (prepared according to the method of Weisler $e t$ al. 1947) was used for detecting the $\gamma$ - and $\delta$-tocopherols. The $\gamma$-compound gives a dark-purple spot, whereas the $\delta$ compound gives a red spot readily distinguishable from the $\gamma$-spot. Under these conditions the $\alpha$ - and $\beta$-compounds do not give spots.

\section{Separation of synthetic mixtures of the tocopherols}

Mixtures of racemic $\alpha$-, $\beta$ - and $\delta$-tocopherols were readily separated using $75 \%(v / v)$ aqueous ethanol as the mobile phase and Vaseline-coated filter papers as the stationary phase; the $\beta$ - and $\gamma$-isomers could not be separated. The $R_{F}$ values of the tocopherols were: $\alpha, 0.50 ; \beta, 0.72 ; \gamma, 0.72$; $\delta, 0 \cdot 84$. These values were the same whether the tocopherols were used alone or mixed with other tocopherols.

Inability to separate the $\beta$ - and $\gamma$-isomers is not a serious 
drawback in examining natural products because the $\beta$ compound occurs only in wheat products. In addition, if a spot is obtained at $R_{F}=0.72$ using the $2: 2^{\prime}$-dipyridyl-ferric chloride reagents, the presence of $\gamma$ can be ascertained by using the 0 -dianisidine spray.

As little as $3 \mu \mathrm{g}$. of any of the tocopherols can be readily detected with the dipyridyl-ferric chloride reagents and even less of the $\gamma$-and $\delta$-compounds can be detected with the sodium carbonate-o-dianisidine spray.

\section{Extraction of the tocopherols from biological material}

Methods for the extraction of tocopherols from natural products are largely based on methods for fat extraction (Quaife \& Harris, 1948; Quaife \& Dju, 1949). Lipids and sterols interfered with the running of the tocopherols on the chromatograms and were consequently removed. The lipids were hydrolysed in the presence of pyrogallol (Tošic \& Moore, 1945) to prevent loss of tocopherols by oxidation, and the unsaponifiable matter freed from sterols by crystallizing from methanol solution at $-15^{\circ}$. Carotene in large amounts also caused interference on the chromatograms; consequently the carotenoids were removed by absorbing them from benzene solution on Floridin Earth according to the method of Emmerie \& Engel (1939). The Floridin Earth 'specially prepared for use in Emmerie's test for tocopherols' as supplied by British Drug Houses Ltd. was found to cause some destruction of the tocopherols. Glavind, Kjølhede \& Prange (1942) have also reported that in the passage of tocopherols through earths of high surface activity a considerable amount of the tocopherols is oxidized. They prevented the oxidation by boiling the earth (1.5-2.0 g.) with $\mathrm{SnCl}_{2}(0 \cdot 25 \mathrm{~g}$.) and $10 \mathrm{~N}-\mathrm{HCl}(5-8 \mathrm{ml}$.) before using it. This procedure has been adopted in the present work, the heated mixture being introduced into an adsorption tube and washed free from acid with ethanol $(5 \mathrm{ml}$.) followed by benzene $(5 \times 5 \mathrm{ml}$. portions). Using this method of preparation quantitative recoveries of the tocopherols have been obtained using as little as $10 \mu \mathrm{g}$. of tocopherols. Some, if not all, of the destruction of the tocopherols when using B.D.H. Floridin Earth was due to the presence of iron in the earth.

\section{Examination of tocopherol mixtures present in natural oils}

Vegetable oils are among the richest natural sources of the tocopherols, and consequently afford excellent starting materials for testing the method described. The oils were hydrolysed (Tošić \& Moore, 1945) and the unsaponifiable fraction in benzene passed through a prepared column $(30 \times 13 \mathrm{~mm}$.) of Floridin Earth (see above). For each oil the filtrate was evaporated under reduced pressure and the residue dissolved in warm methanol. After removing the sterols by crystallizing at $-15^{\circ}$, the mother liquors were applied to the starting line of the paper. The tocopherols found in several oils are shown in Table 1.

Treatment of the chromatogram of the wheat-germ oil with the $2: 2^{\prime}$-dipyridyl-ferric chloride reagents gave, in addition to spots at the positions corresponding to the $\alpha$ - and $\beta$-tocopherols, a distinct spot at $R_{F}=0.93$. Ammoniacal silver nitrate was reduced by the substance, but a spot was not obtained with the $o$-dianisidine reagent. The identity of this substance was not ascertained. The spot at $R_{F}=0.72$ was $\beta$ - and not $\gamma$-tocopherol because spraying with sodium carbonate and diazotized $o$-dianisidine failed to give a spot. None of the other oils examined gave an 'apparent tocopherol' spot in this way, indicating that all the interfering substances had been removed prior to chromatography.

\section{Table 1. Tocopherols found to be present in various natiral products}

\begin{tabular}{|c|c|c|c|c|}
\hline Substance & $\alpha$ & $\beta$ & $\gamma$ & $\delta$ \\
\hline Arachis oil & + & . & + & . \\
\hline Cottonseed oil & + & . & + & . \\
\hline Soya-bean oil & + & . & + & + \\
\hline Wheat-germ oil. & + & + & . & . \\
\hline Cocksfoot grass & + & $\cdot$ & - & - \\
\hline Fescue grass & + & . & . & . \\
\hline Timothy grass & + & . & . & . \\
\hline Cows' blood ) (cows at grass) & + & $\cdot$ & : & - \\
\hline Cows' milk \} (cows at grass) & + & . & . & . \\
\hline
\end{tabular}

In the soya-bean oil chromatogram three spots with $\boldsymbol{R}_{F}$ values $0.50,0.72$ and 0.84 were obtained with the EmmerieEngel reagents. The presence of $\gamma$ - and $\delta$-tocopherols was confirmed by means of the $o$-dianisidine spray.

\section{Tocopherols occurring in other natural products}

The importance of the tocopherols in the nutrition of farm animals is becoming increasingly apparent. Consequently, three different species of grass, timothy (Phleum pratense), cocksfoot (Dactylis glomerata) and fescue (Festuca pratensis), have been examined to determine which tocopherols they contain. The grasses were extracted with ethanol in a Soxhlet apparatus and the ethanol solution extracted with light petroleum (Quaife \& Harris, 1948). The unsaponifiable fractions were examined in the same way as those from the oils. Only $\alpha$-tocopherol was found in the grasses (Table 1) but there is present in cocksfoot a substance which gives a purple colour with $\mathrm{Na}_{2} \mathrm{CO}_{3}$ and diazotized $o$-dianisidine. This unidentified substance moved only a short distance from the starting line on the chromatogram ( $R_{p}$ approx. 0.05).

The blood and milk of cows feeding on the three grasses contained $\alpha$-tocopherol only. Because of the relatively low levels of tocopherols in cows' blood and milk (about 800 and $150 \mu \mathrm{g} . / 100 \mathrm{ml}$. respectively), even when the dietary intake is $10 \mathrm{~g}$. or more daily (Cabell \& Ellis, 1942), about $10 \mathrm{ml}$. of blood serum and $50 \mathrm{ml}$. of milk are necessary for a satisfactory analysis to be made.

\section{DISCUSSION}

The Emmerie-Engel method for determining tocopherols depends on the reduction of alcoholic ferric chloride followed by reaction of the ferrous salt with $2: 2^{\prime}$-dipyridyl to give a red ferrous-dipyridyl complex. Since other substances likely to be present in the fat-soluble fraction of natural products can also reduce ferric to ferrous iron, these interfering substances must be removed in order to obtain the true tocopherol content. Even then comparison with biological assays is difficult because of the different biological potencies of the tocopherols, and the fact that the Emmerie-Engel reaction does not distinguish between the different compounds. 
The method described in the present work allows the purity of the solution under test for tocopherols to be assessed and also enables the separation of the commonly occurring $\alpha-, \gamma$ - and $\delta$-tocopherols to be achieved. Applications of the method to the examination of several oils indicate the usefulness of the method. For example, the presence of $\delta$ tocopherol in soya-bean oil is readily ascertained, whereas its existence escaped detection by conventional methods for many years. In addition, the substance in cocksfoot grass which gives a colour with diazotized $o$-dianisidine is shown to be different from any of the known tocopherols in its behaviour on the chromatogram. Similarly, a non-tocopherol ferric-reducing substance which is not removed by the saponification, adsorption and crystallization processes is present in wheat-germ oil.

Although the method will probably not be readily applicable to routine analysis, its value for reliably detecting the presence of naturally occurring tocopherols is apparent. Application of the method to the quantitative analysis of tocopherol mixtures is being undertaken and will be the subject of a further communication.

\section{SUMMARY}

1. A method is described for the detection of $\alpha$-, $\beta$-, $\gamma$ - and $\delta$-tocopherols by filter-paper chromatography.

2. The method has been used for study of the tocopherols in various vegetable oils and grasses and also in blood and milk.

The author is grateful to Dr J. Green, Vitamins Ltd., for discussions on the use of Floridin Earth, and to the following for generous gifts of material: Prof. P. D. Boyer, Dr H. Dam, Dr A. Emmerie and Dr M. L. Quaife, Messrs J. Bibby and Son Ltd., Roche Products Ltd. and Vitamins Ltd.

\title{
REFERENCES
}

Baxter, J. G., Lehman, R. W., Hove, E. L., Quaife, M. L., Weisler, L. \& Stern, M. H. (1947). Biol. Symp. 12, 484.

Cabell, C. A. \& Ellis, N. R. (1942). J. Nutrit. 23, 633.

Consden, R., Gordon, A. H. \& Martin, A. J. P. (1944). Biochem. J. 38, 224.

Emmerie, A. (1949). Ann. N.Y. Acad. Sci. 52, 309.

Emmerie, A. \& Engel, C. (1938). Rec. Trav. chim. Pays-Bas, 57, 1351.

Emmerie, A. \& Engel, C. (1939). Rec. Trav. chim. Pays-Bas, $58,283$.
Glavind, J., Kjølhede, K. T. \& Prange, I. (1942). Kem. Mannedsblad. 23, 43.

Quaife, M. L. \& Dju, M. Y. (1949). J. biol. Chem. 180, 263.

Quaife, M. L. \& Harris, P. L. (1948). Anal. Chem. 20, 1221, Tošić, J. \& Moore, T. (1945). Biochem. J. 39, 498.

Weisler, L., Robeson, C. D. \& Baxter, J. G. (1947). Anal. Chem. 19, 906.

Williams,.R. J. \& Kirby, H. M. (1948). Science, 107, 481.

Winteringham, F. P. W., Harrison, A. \& Bridges, R. G., (1950). Nature, Lond., 166, 999.

\section{Flavin-adenine Dinucleotide and Diaphorase in Resting and Germinated Spores, and Vegetative Cells of Bacillus subtilis and Bacillus megatherium}

\author{
BY ROSEMARY E. J. SPENCER AND JOAN F. POWELL \\ Microbiological Research Department (Ministry of Supply), Porton, Wiltshire
}

(Received 22 May 1951)

There are conflicting reports on the respiration rate of resting bacterial spores, but it is generally agreed that it is lower and less sensitive to cyanide than that of vegetative cells (Tarr, 1933; Keilin \& Hartree, 1947). Keilin \& Hartree (1949) have also found that although the spores of Bacillus subtilis National Collection of Type Cultures 85(N.C.T.C.) contain considerable amounts of unidentified haematin compounds, their cytochrome content is only $6 \%$ of that of vegetative cells, and more recently Chaix \& Roncoli (1950) have observed development from an atypical to a classical cytochrome spectrum during the growth of several strains of $B$. subtilis. These findings suggest that bacterial spores differ from vegetative cells in possessing an alternative to the cytochromecytochrome oxidase system, possibly in the form of a flavoprotein reacting with oxygen, either directly or through an unidentified haematin catalyst (Slater, $1949 a, b$ ) and that this flavoprotein system may be replaced by the cytochrome system as growth proceeds.

It is interesting to note that respiration, relatively insensitive to cyanide, has also been demonstrated in resting spores of Neurospora crassa (Goddard \& Smith, 1938) and in unfertilized Arbacia eggs (Korr, 1939). The latter were shown to contain haematin compounds but no cytochrome (Ball \& Meyerhof, 